\title{
Nuclear Accidents in Fukushima, Japan, and Exploration of Effective Decontaminant for the ${ }^{137}$ Cs-Contaminated Soils
}

\author{
Hajime Iwata*, Hiroyuki Shiotsu*, \\ Makoto Kaneko* and Satoshi Utsunomiya*,** \\ Department of Chemistry, Kyushu University, Hakozaki, Higashi-ku, Fukuoka \\ elopan
}

\section{Introduction}

\subsection{A brief summary of the accidents at the Fukushima Dai-ichi nuclear power plant and the release of radionuclides to the environment}

Nuclear accident at the Fukushima Dai-ichi nuclear power plant (FDNPP), which is located $230 \mathrm{~km}$ north of downtown Tokyo, was the most recent tragedy in the nuclear society. The total release of radioactivity was estimated to be $6.3 \times 10^{17} \mathrm{~Bq}$, which is approximately onetenth of the total radioactivity released from the Chernobyl $\left(5.2 \times 10^{18} \mathrm{~Bq}\right)($ TEPCO, 2011). The International Atomic Energy Agency (IAEA) has recently announced the International Nuclear and Radiological Event Scale (INRES) of the Fukushima accident to be level 7.

There are six nuclear reactors in the FDNPP (Fig. 1). These boiling water reactors (BWRs) generated 460 (reactor 1), 784 (reactor 2-5), and 1100 (reactor 6) mega watt. Thirty-two out of 548 fuel rods were mixed oxide fuel (MOX) in the reactor 3, of which the Pu concentration in each fuel pellet contains up to $10 \mathrm{wt} \%$ of plutonium.

When the earthquake with the magnitude of 9.0 hit the east Japan on March 11th, the reactors 1-3 were in operation. These reactors immediately shut down by inserting the control rods and the nuclear reaction stopped in the reactors 1-3. However, the catastrophic Tsunami with the water level unexpectedly as high as $\sim 15 \mathrm{~m}$ caused serious damage in the power plant, including the power outage and the following cut-off in the emergency power supply (Narabayashi \& Sugiyama, 2011). The power plant was facilitated with a breakwater based on the expected Tsunami level as high as $5.7 \mathrm{~m}$, which was far not enough for the Tsunami this time. The power outage caused serious problems, because the cut-off in the emergency electric system stopped the watering systems cooling down the nuclear reactor cores. The loss of water supply and continuous escape of steamed water to the pressure suppression system lowered the level of the cooling water, resulting in full or partial exposition of the fuel rods. The temperature of nuclear fuels increased upon exposing out

\footnotetext{
${ }^{*}$ All authors contributed equally

${ }^{* *}$ Author for correspondence
} 

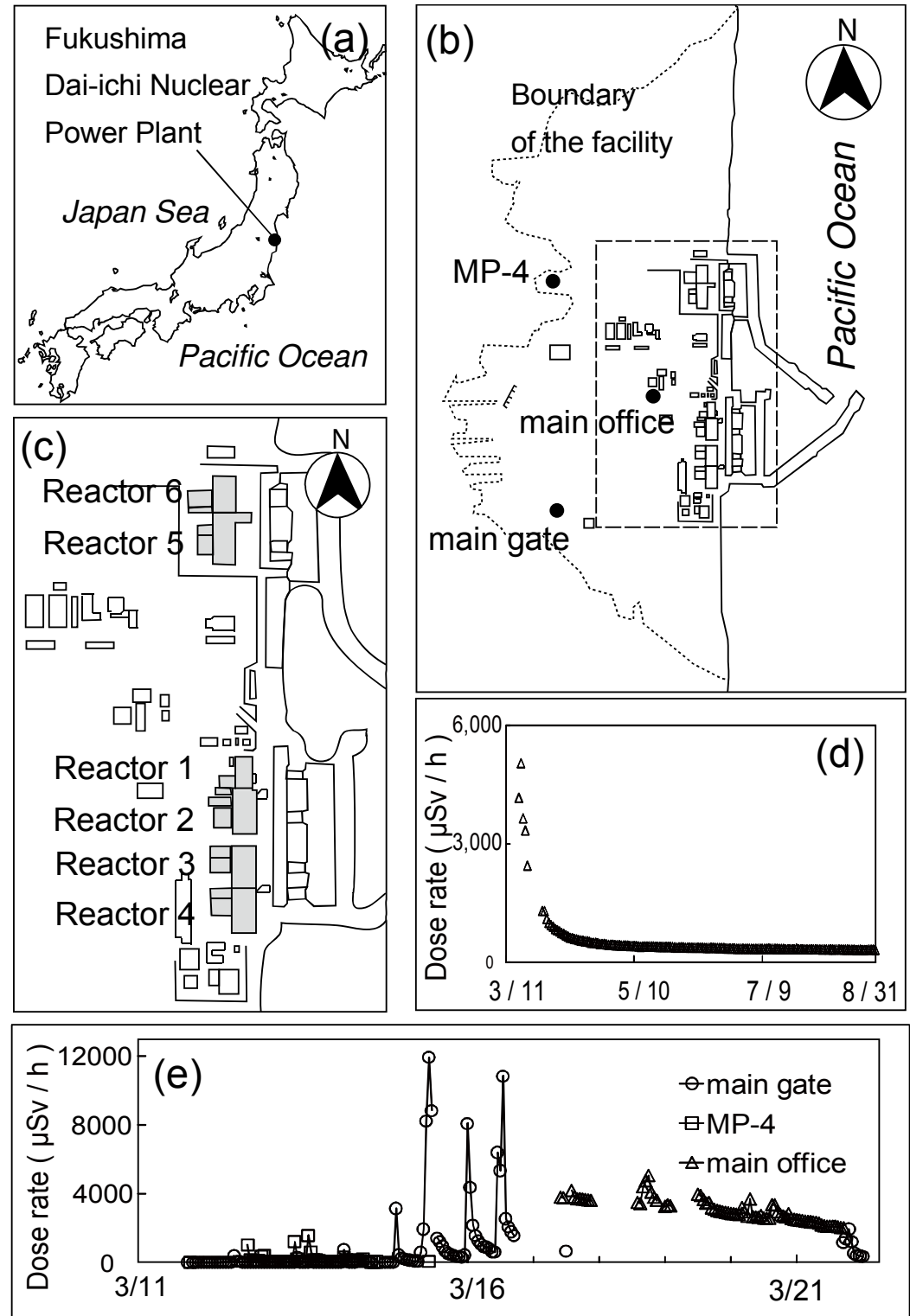

Fig. 1. The Fukushima Dai-ichi Nuclear Power Plant (FDNPP) and radioactivities in the facility reported by Tokyo Electric Power Company (TEPCO). (a) The map of Japan showing the location of the FDNPP. (b) The map of the FDNPP with the location of monitoring posts. (c) A magnified illustration showing the position of the reactors 1-6. (d) Time-dependent radioactivity monitored at the main office reported by TEPCO. (e) Time-dependent radioactivities during the first 10 days after the earthquake detected at three monitoring posts. Data from the TEPCO web site (TEPCO, 2011). 
of water, and at the elevated temperature, $\mathrm{Zr}$ metal alloy that clads the fuel reacted with water producing $\mathrm{H}_{2}$ as the following expression:

$$
\mathrm{Zr}+2 \mathrm{H}_{2} \mathrm{O}->\mathrm{ZrO}_{2}+2 \mathrm{H}_{2}
$$

A part or a whole body of the fuel melted down due to the temperature increase derived from the decay heat beyond the melting temperature of the $\mathrm{UO}_{2}$ without cooling water. The melted core broke through the pressure vessel and fission products leaked into the containment vessel. Subsequently, these fission products were released from the containment vessel due to the high inside pressure as well as $\mathrm{H}_{2}$ gas. The hydrogen gas accumulated in the reactor building. As a result, $\mathrm{H}_{2}$ explosion occurred at the operation floor in the reactor 1, 3, 4 and possibly in the pressure control unit of the reactor 2 .

According to the calculation by Naito (2011), the amount of the produced $\mathrm{H}_{2}$ gas was estimated to be $\sim 500 \mathrm{~kg}$ and the pressure inside the reactor 1 building reached $\sim 5 \mathrm{~atm}$ at the time of "deflagration". In the case of the reactor 3 , the pressure was estimated as high as $\sim 60$ atm during the "detonation". The reactor 4, which hosted 1,331 spent nuclear fuels in the storage pool, was in shut down mode for the regular check and maintenance at the time of earthquake. However, the excess $\mathrm{H}_{2}$ gas generated in the reactor 3 in-flowed through the pipelines connecting between the reactors 3 and 4 .

During the series of those initial crises, various efforts were made to cool down the reactor cores of the reactors 1-3 by using seawater and subsequently freshwater. This water injection generated a large amount of radioactive waste waters, of which the total amounts of the injected waters until May 31 were 13,630 $\mathrm{m}^{3}, 20,991 \mathrm{~m}^{3}$, and 20,625 $\mathrm{m}^{3}$ for the reactors 1, 2, and 3, respectively (TEPCO, 2011). The series of major events during the initial stage of the accident at the FDNPP is summarized in Table 1.

There are two serious issues raised by the series of accidents. One is the release of the large amount of highly radioactive water to the near-field environment, of which the solvent is a mixture of freshwater and seawater. $10,393 \mathrm{~m}^{3}$ of radioactive water with the total radioactivity of $1.5 \times 10^{15} \mathrm{~Bq}$ was released out to the ocean, while $19,770 \mathrm{~m}^{3}$ of the waste water was stored and isolated in the main processing building and the high temperature calcinator building (TEPCO, 2011). A new circulation system of cooling water was installed and started operating on June 27, which is equipped with a series of filtering and ionexchanging columns.

Although a large amount of radionuclides was locally released to the Fukushima Pacific coast, the results of monitoring radioactivity revealed the minimum contamination in seawater owing to dilution by almost infinite volume of seawater. As far as the water purifying system operates, the contamination will keep decreasing. The high-level radioactive waters stored in the main processing building and the high temperature calcinator building, of which the total amount is $19,770 \mathrm{~m}^{3}$, have been treated by means of zeolite-based materials adsorbing radionuclides, namely Cs radioisotopes. On the other hand, immediately after the accident, a number of experiments were systematically conducted by the research groups at some Japanese universities to evaluate the adsorption coefficients of $\mathrm{I}^{-}$and $\mathrm{IO}_{3}-$ to a large set of adsorbents in the mixed waters of seawater and freshwater; that is, with high ionic strength. The highest adsorption coefficient $\left(K_{\mathrm{d}} \sim 10^{5}\right)$ was found in the use of cobalt ferrocyanide in seawater. 


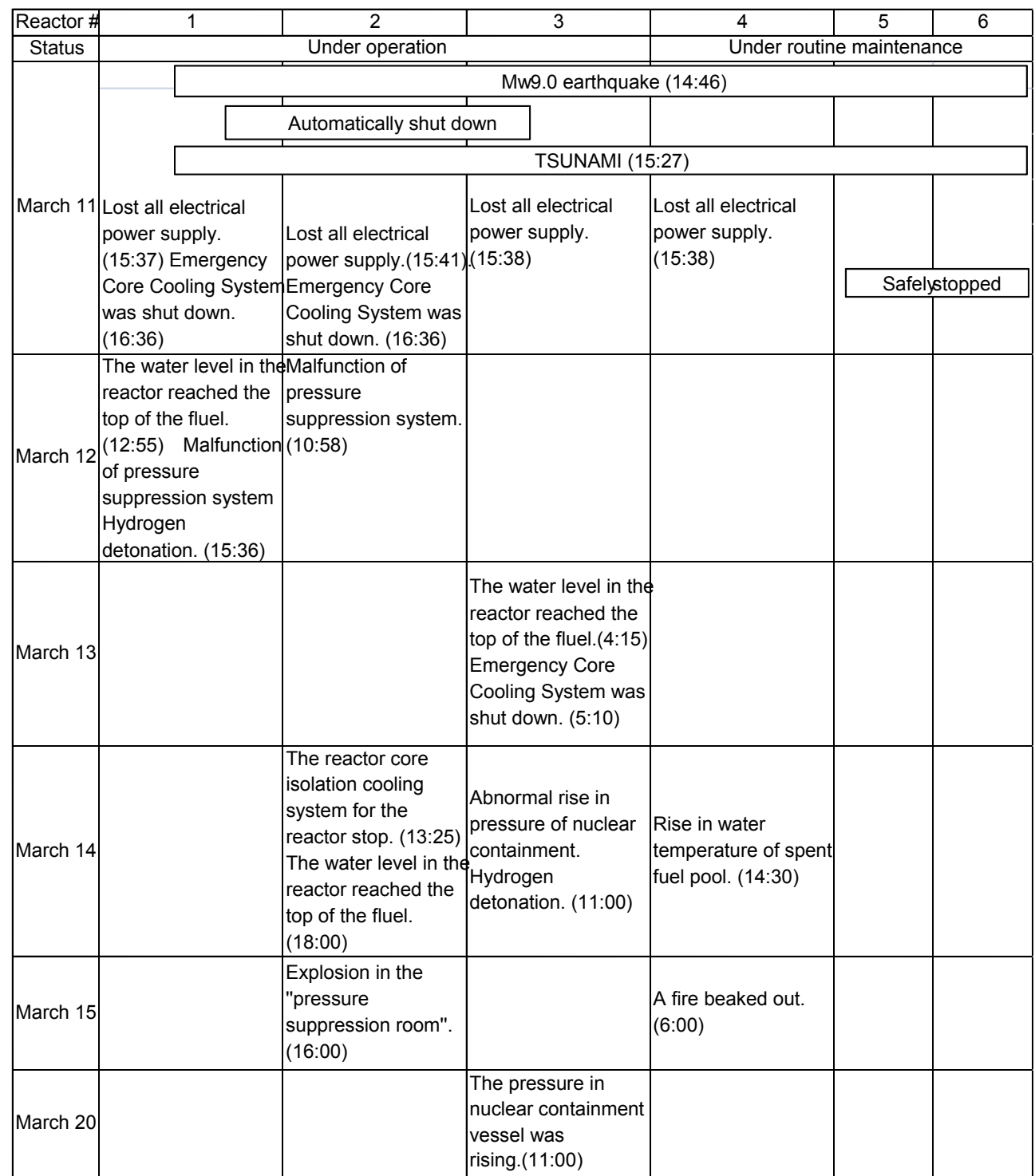

Table 1. A summary of the major events occurred in the nuclear reactors at the FDNPP during the initial stage of the series of accidents.

The other issue is contamination of surface soils in the vicinity of the FDNPP. Figure 1d shows the released radioactivities to ambient atmosphere for the period till the end of August 2011, indicating dramatic decrease in the radioactivity by June; approximately 2 millionth from the time of accident. As of August in 2011, TEPCO is constructing the shield to cover the collapsed top part of the reactor buildings to completely shut off the release of 
radionuclides, and further contamination will be stopped. However, a large area of the Fukushima prefecture has been already contaminated with ${ }^{137} \mathrm{Cs}\left(\mathrm{T}_{1 / 2}=30.07 \mathrm{y}\right),{ }^{134} \mathrm{Cs}\left(\mathrm{T}_{1 / 2}\right.$ $=2.062 \mathrm{y}),{ }^{131} \mathrm{I}\left(\mathrm{T}_{1 / 2}=8.02 \mathrm{~d}\right)$, and minor ${ }^{90} \mathrm{Sr}\left(\mathrm{T}_{1 / 2}=29.1 \mathrm{y}\right)$, as high as several hundreds $\mathrm{mSv} / \mathrm{h}$ near the power plant. Other fissiogenic elements released into the surrounding environment are summerized in Table 2. The total volume of the contaminated soils was estimated to be $28,785,000 \mathrm{~m}^{3}$ (MEXT, 2011).

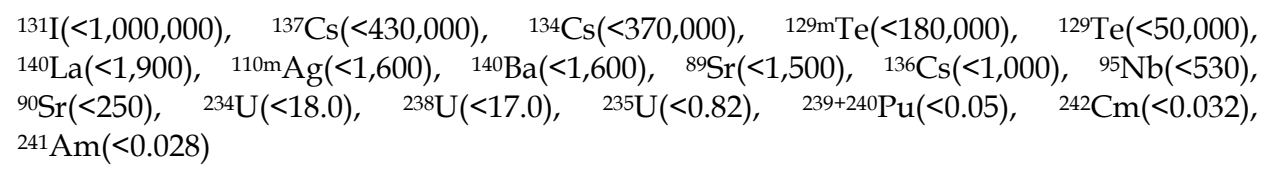

Table 2. List of the released fissiogenic elements detected in soils in the vicinity of the FDNPP. The values in parenthesis stand for the maximum concentration $(\mathrm{Bq} / \mathrm{kg})$ reported to date, which were compiled from the TEPCO database (TEPCO, 2011).

For predicting the distribution and mobility of the released radionuclides, the System for Prediction of Environmental Emergency Dose Information (SPEEDI) was formerly developed and applied to the case of Chernobyl accident (Chino et al., 1986). The SPEEDI was also utilized for the case of the Fukushima accident and the prediction of radioactivity was opened to public (Chino et al., 2011). On the other hand, owing to the well-established network of monitoring post and the rigorous sampling campaign conducted after the accident, the dose rate was measured and the dose accumulation was predicted for the one year duration since the accident.
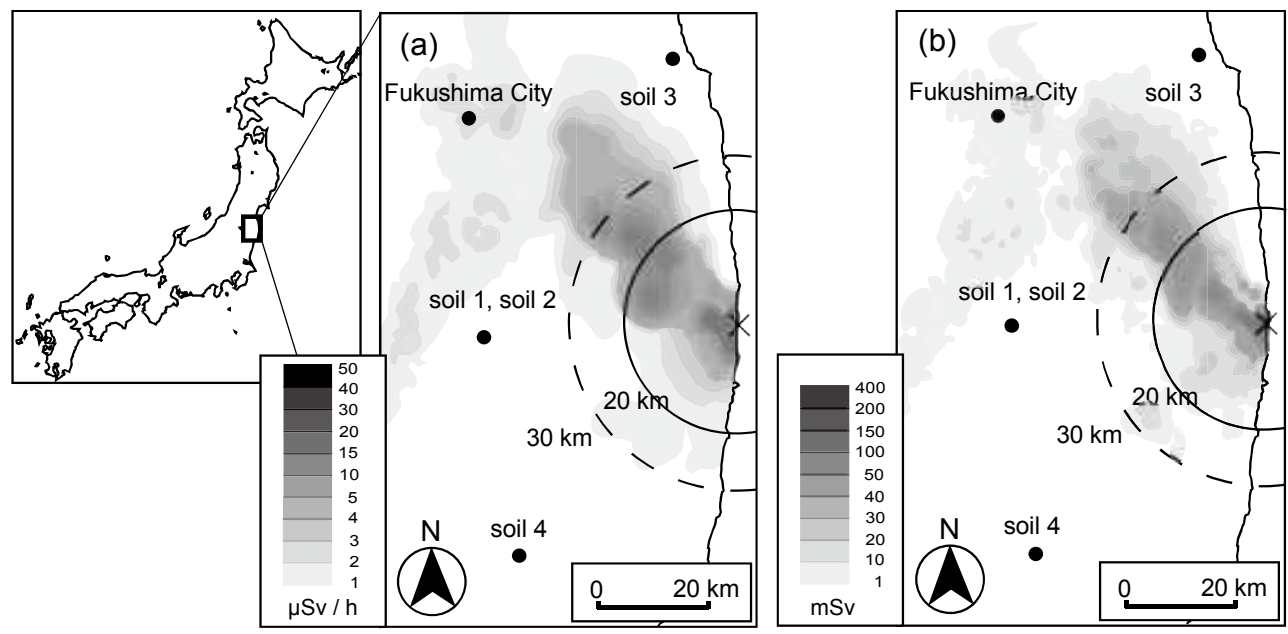

Fig. 2. The maps of the radioactivity distribution measured $1 \mathrm{~m}$ above the ground. Data from Ministry of Education, Culture, Sports, Science and Technology, Japan (MEXT, 2011). (a) Measured radioactivity on $8 / 11 / 2011$. (b) Prediction of the accumulated radioactivity for one year period; 3/11/2011-3/11/2012. 
Figures $2 \mathrm{a}$ and $\mathrm{b}$ show the map of the radioactivity on 8/11/2011 near ground level (a) and the contour map of the accumulated dose estimated for the period from March 11, 2011 to March 11, 2012 (b). The highly contaminated area is characteristically elongated towards the north-west covering Futaba, Namie town and Iidate village. This biased distribution is attributed to the wind direction during the explosive events. In the area near the FDNPP, the wind was often directed to the northwest because of the sea-breeze in day time and the topological characteristics (Yamazawa and Hirao, 2011). Especially, the amount of released radionuclides on March 15th was estimated to be one to two orders of magnitude greater than that in the other days and the wind was directed toward the northwest (Yamazawa and Hirao, 2011). Because of the biased wind direction, ${ }^{134} \mathrm{Cs},{ }^{137} \mathrm{Cs}$ and ${ }^{131} \mathrm{I}$ in the surface soils at Komiya, Iidate village, were detected to be $\sim 140,000 \mathrm{~Bq} / \mathrm{kg}, \sim 170,000 \mathrm{~Bq} / \mathrm{kg}$, and $\sim 1,100$ $\mathrm{Bq} / \mathrm{kg}$, respectively, as of June 5, 2011, where is even $35 \mathrm{~km}$ distant from the FDNPP (MEXT, 2011). The initially reported values analyzed for the soil from Tsushima, Namie town, located $30 \mathrm{~km}$ distant from the FDNPP revealed much higher dose rate; 282,000 Bq/ $\mathrm{kg}$ for ${ }^{134} \mathrm{Cs}, 290,000 \mathrm{~Bq} / \mathrm{kg}$ for ${ }^{137} \mathrm{Cs}$, and 710,000 Bq/kg for ${ }^{131} \mathrm{I}$ on March 30, 2011 (NSCJ, 2011).

\section{Exploration of efficient decontamination protocol}

\subsection{Background of experiments}

Because the large-scale contamination in the vicinity of the FDNPP is mainly derived from ${ }^{137} \mathrm{Cs}$, the efficient protocol to decontaminate Cs that already adsorbed to the soils is highly demanded in Fukushima prefecture and even in near Tokyo.

Adsorption/desorption phenomena of Cs to/from various geological media have been extensively investigated in the previous studies to evaluate the capacity of Cs immobilization by natural or artificial buffer materials (Comans \& Hockley, 1992; Khan et al. 1994; Hsu \& Chang, 1994; Seaman et al., 2001; Hassan 2005; Mon et al., 2005; Bellenger \& Staunton, 2008; Rajec \& Domianova, 2008; Wang et al., 2010; Yildiz et al. 2011) or to understand the migration of Cs in the specific contaminated sites (Zachara et al., 2002; Liu et al., 2003; Steefel et al., 2003; Missana et al., 2004; Bouzidi et al., 2010).

In the present study, Cs adsorption and desorption experiments have been carried out in laboratory using non-contaminated soils collected from Fukushima. It is noted that the goal of this chapter is not to discuss either kinetics or mechanism of Cs adsorption/desorption process. We demonstrate detailed characterization of soil materials utilizing a variety of high resolution techniques including electron microscopy to understand; i) the type of clay minerals that strongly bound to Cs, ii) quantity of adsorbed and desorbed Cs. We also test a series of desorption experiments exploring the most effective protocol to remove Cs from the contaminated soils.

\subsection{Experimental methods}

\subsubsection{Soil samples}

For adsorption and desorption experiments in the present study, we have collected four surface soils from different locations in Fukushima prefecture (plotted in Fig. 2) in June 2011. These sites have not been contaminated, of which the radioactivities are as low as the background level. 
The surface area of the soil samples was analyzed by a Brunauer Emmett Teller (BET) method using Quantachrome AUTOSORB-1 with $\mathrm{N}_{2}$ gas. Each sample was heated at $120{ }^{\circ} \mathrm{C}$ for $1.5 \mathrm{~h}$ to remove adsorbed water prior to the mesurement.

Cation exchange capacity (CEC) was also determined for all samples. About $2.0 \mathrm{~g}$ soil sample was placed in $30 \mathrm{ml}$ of $0.1 \mathrm{M} \mathrm{BaCl}_{2}$ (aq) and intermittently shaken for $1 \mathrm{~h}$, followed by centrifugation at $6000 \mathrm{rpm}$ for $10 \mathrm{~min}$. This procedure was repeated for three times to completely replace exchangeable cations with Ba. Subsequently, the solid phase was contacted with $30 \mathrm{ml}$ of $0.0025 \mathrm{M} \mathrm{BaCl}_{2}$ (aq) for $14 \mathrm{~h}$. Then, the treated soil was contacted with $0.02 \mathrm{M} \mathrm{MgSO}_{4}$ (aq) for $28 \mathrm{~h}$ and centrifuged. The supernatant was filtered by $0.20 \mu \mathrm{m}$ syringe filter and the $\mathrm{Mg}$ concentration was measured by an atomic absorption spectrometry (AA, Shimadzu AA-6300). The CEC can be calculated using the following expression:

$$
\begin{aligned}
& C_{1}^{\prime}=C_{1} \times \frac{\left(a+m_{2}-m_{1}\right)}{a} \\
& C E C=\frac{a\left(C_{1}^{\prime}-C_{2}\right)}{m_{1}} \times 100
\end{aligned}
$$

$C_{1}$ : initial Mg concentration (mol/l)

$C_{1}$ ': corrected initial $\mathrm{Mg}$ concentration (mol/l)

$\mathrm{C}_{2}$ : final $\mathrm{Mg}$ concentration ( $\left.\mathrm{mol} / \mathrm{l}\right)$

$m_{1}:$ dry soil mass $(\mathrm{g})$

$m_{2}$ : wet soil mass $(\mathrm{g})$

$a: 0.02 \mathrm{~mol} / 1 \mathrm{MgSO}_{4}$ volume $(\mathrm{ml})$

Fundamental information and properties of the soils used in the experiments are

\begin{tabular}{|c|c|c|c|c|}
\hline Sample & Soil 1 & Soil 2 & Soil 3 & Soil 4 \\
\hline \multirow[t]{2}{*}{ Location } & Miharu town & Miharu town & Shinchi town & Furudono town \\
\hline & $\begin{array}{l}\text { N37²24'30.8', } \\
\text { E14029'59.7" }\end{array}$ & $\begin{array}{l}\text { N37 } 23 ' 37.5^{\prime \prime}, \\
\text { E14030'14.6" }\end{array}$ & 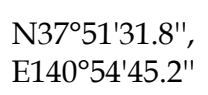 & 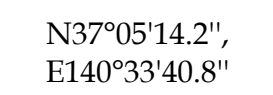 \\
\hline Occurrence & Temple yard & Garden soil & Park & $\begin{array}{c}\text { Elementary school } \\
\text { play yard }\end{array}$ \\
\hline Depth & $0-5 \mathrm{~cm}$ & $0-5 \mathrm{~cm}$ & $10-15 \mathrm{~cm}$ & $0-5 \mathrm{~cm}$ \\
\hline $\begin{array}{l}\text { Surface area } \\
\left(\mathrm{m}^{2} / \mathrm{g}\right)\end{array}$ & 2.32 & 5.15 & 27.8 & 7.82 \\
\hline $\mathrm{CEC}(\mathrm{cmol} / \mathrm{kg})$ & $1.24 \pm 0.18$ & $1.77 \pm 0.15$ & $4.53 \pm 0.02$ & $2.49 \pm 0.28$ \\
\hline
\end{tabular}
summarized in Table 3.

Table 3. Basic information and properties of the four non-contaminated soils collected in Fukushima. 


\subsection{Adsorption / desorption batch experiments}

Adsorption experiment was carried out in batch system. About $50 \mathrm{~g}$ of soil sample was contacted with 11 of $\mathrm{CsCl}$ solution with three different Cs concentrations: 10, 1.0, and 0.1 mM. $3 \mathrm{ml}$ of supernatant was collected at 1, 2, 4, 8, 24, 48 hours, 4, 7, 14, 21 and 28 days, and filtered with a $0.2 \mu \mathrm{m}$-pore-sized syringe filter. The filtrates were diluted to $10^{3}-10^{5}$ times with milli-Q water for the solution analysis.

After the adsorption experiment, the soil was separated with $0.2 \mu \mathrm{m}$ pore-sized filter and air-dried at room temperature to prepare the starting materials of batch desorption experiment. Six extractants: deionized water (DW), $0.1 \mathrm{~mol} / 1 \mathrm{KCl}, \mathrm{NH}_{4} \mathrm{Cl}, \mathrm{MgCl}_{2}$, acetic acid, and citric acid, were tested in the desorption experiment. $200 \mathrm{ml}$ of the extractant was contacted with $5 \mathrm{~g}$ of the soil 1 or 3 that preliminarily adsorbed Cs in the $10 \mathrm{mM} \mathrm{CsCl}$ solution. During the desorption experiment, mixture of the soil and solution was continuously agitated. The $1 \mathrm{ml}$ of suspension was collected and filtered through a $0.2 \mu \mathrm{m}-$ pore-sized syringe filter at 1, 2, 4, 8, 24, and 48 hours, 4 and 7 days. The filtrates were diluted to $10^{3}$ times for the solution analysis.

\subsection{Analytical methods}

The Cs concentration in solution was analysed by an inductively coupled plasma mass spectrometry (ICP-MS, Agilent 7500c) in non gas mode with In internal standard. The calibration line was drawn with $0,1,10,50,100,200 \mathrm{ppb}$ and the detection limit of Cs was $\sim 0.1$ ppt.

The major mineral assemblage of the soils was determined by using a powder $X$-ray diffraction (XRD, RIGAKU MultiFlex) equipped with a $\mathrm{Cu}$ target and a reflected beam monochromator. The scan rage was $3^{\circ}-63^{\circ}$ with the scanning speed of $1^{\circ} \mathrm{min}^{-1}$ of $2 \theta$ and the step angle of $0.02^{\circ}$. In addition to the bulk samples, the levigated soil samples were measured to obtain more detailed information on clay minerals. About $15 \mathrm{~g}$ of the soil samples were suspended in DW, ultrasonicated for $5 \mathrm{~min}$. and centrifuged at $1000 \mathrm{rpm}$ for $10 \mathrm{~min}$. The clay-rich portion was separated and air-dried at room temperature on a watch glass. The XRD was performed ranging $3^{\circ}-33^{\circ}$ at the scan speed of $1^{\circ} \mathrm{min}^{-1}$ of $2 \theta$ with the step angle of $0.02^{\circ}$.

Individual particle analysis was performed for the soil samples contacted with $10 \mathrm{mM} \mathrm{CsCl}$ solution by using a scanning electron microscopy (SEM, SHIMADZU SS-550) equipped with energy dispersive X-ray spectroscopy (EDX). Topology-sensitive imaging was conducted at $5 \mathrm{kV}$ of the acceleration voltage and EDX analysis was completed at $25 \mathrm{kV}$. All samples were coated with carbon using a carbon coater (SANYU SC-701C) to make conductivity.

\subsection{Results and discussion}

\subsubsection{Soil characterization by XRD}

The soil samples were first characterized by XRD analysis to determine the major mineral phases and the results are shown in Fig. 3. In all soil samples, the major mineral phases are quartz and feldspar. Amphibole was additionally detected in soil 1 and 2. Peaks of clay minerals were not clearly recognized in these measurements. 

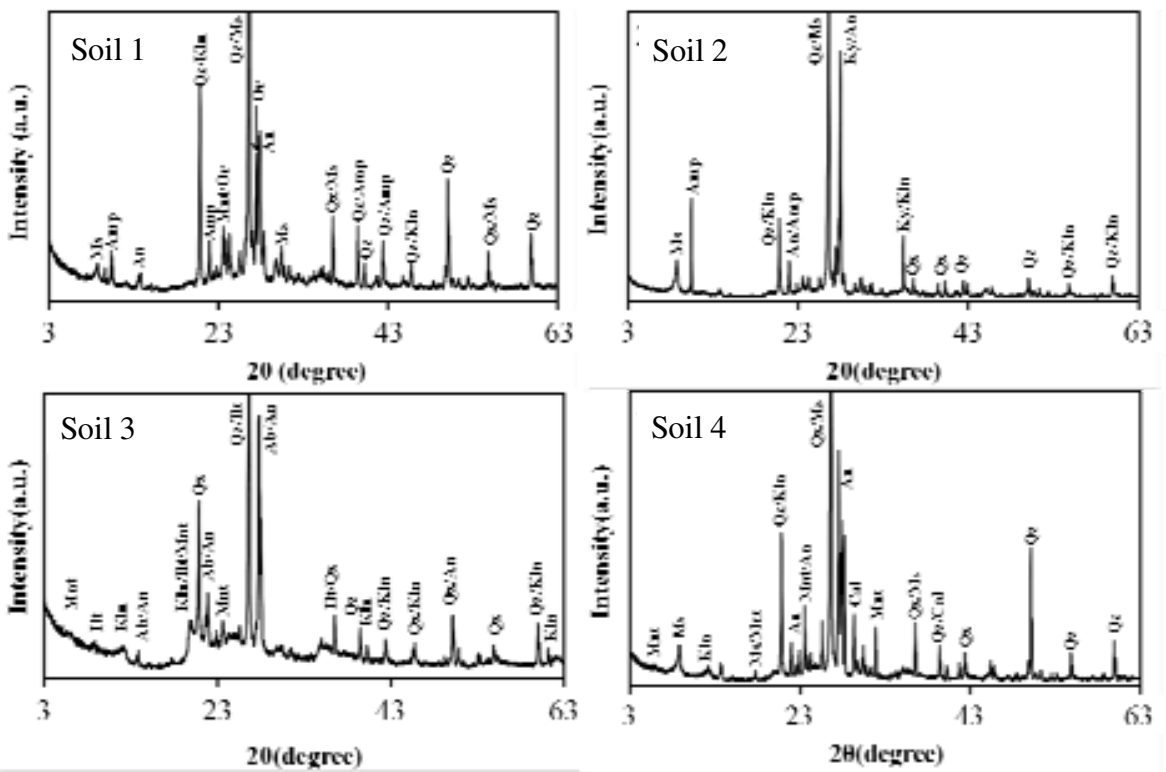

Fig. 3. The results of XRD analysis of the four soils from Fukushima showing the major mineral components. Ms: muscovite, Amp: amphibole, Qz: quartz, Mont: montmorillonite, An: anorthite, Or: orthoclase, Kln: kaolinite, Ilt: illite
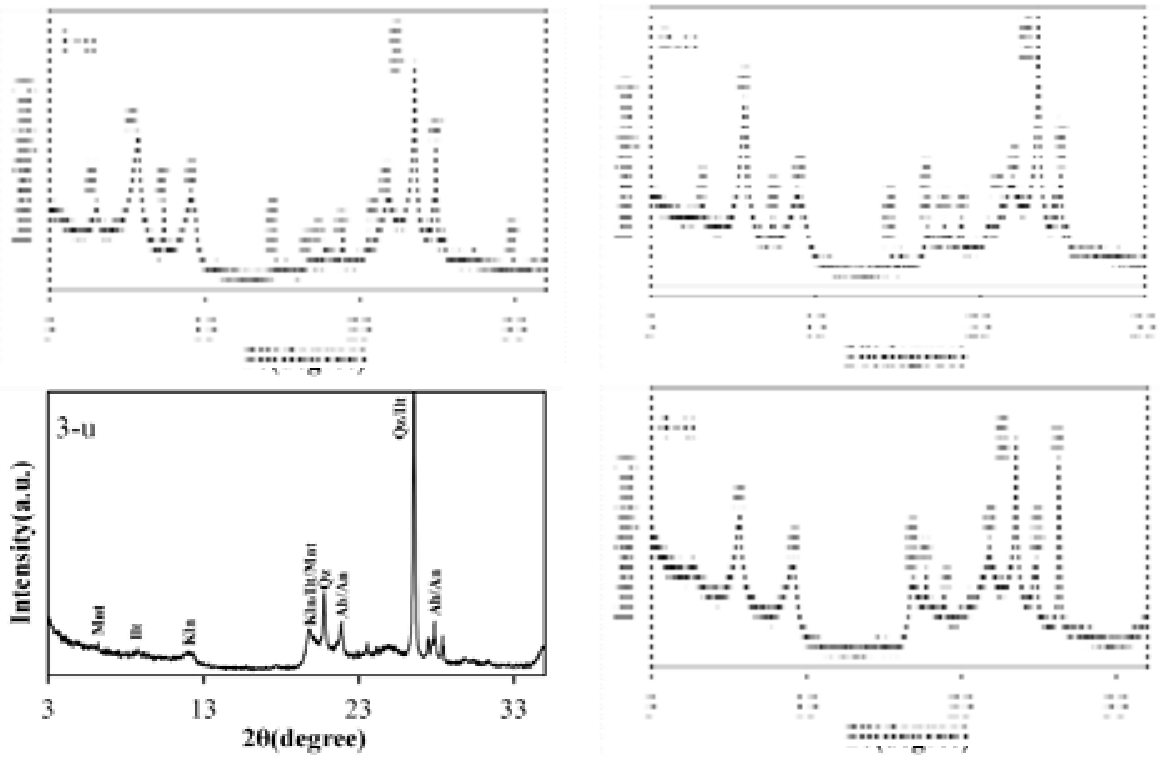

Fig. 4. The results of XRD analysis of the four Fukushima soils after ultrasonication and levigation. The scan range was limited to the lower angles in order to focus on the characterization of clay minerals. 
Hence, these soils were subsequently levigated as described in the experimental method. The results are shown in Fig. 4. All profiles revealed peaks at $\sim 7, \sim 10$, and $\sim 14 \AA$, which correspond to kaolinite, muscovite/illite, and montmorillonite/chlorite, respectively, although the relative intensities at these peak positions vary depending on the soil origion. The soil 3 contained the least amount of sheet silicate minerals. Ethylene glycol (EG) treatment (data not shown here) allowed to distinguish presence of chlorite and smectite, and the peak at $\sim 14 \AA$ remained in all soil samples, indicating that the major phase responsible for $\sim 14 \AA$ peak is chlorite.

\subsubsection{Cesium adsorption to the Fukushima soils}

Table 4 summarizes the time-dependent Cs concentration in the solutions during the adsorption experiments. The data were also plotted in Fig. 5. They reveal that the Cs concentration drastically decreased after contacting the soils. The Cs concentration reached the apparent equilibrium after 336 hours in most of the soils. The time to reach the apparent equilibrium was almost the same for all three initial Cs-concentrations: $10^{-1}, 10^{0}$, and $10^{1}$ $\mathrm{mM}$. The distribution ratio $\left(K_{\mathrm{d}}\right)$ between soil and solution was calculated by the following equation:

$$
K_{\mathrm{d}, \text { adsorption }}=\frac{\left(C_{i}-C_{f}\right)}{C_{f}} \times \frac{W_{l}}{W_{s}}
$$

$C_{\mathrm{i}}$ : the initial Cs concentration (mol/l)

$C_{\mathrm{f}}$ : the final Cs concentration $(\mathrm{mol} / \mathrm{l})$

$W_{1}$ : the solution volume (l)

$W_{\mathrm{s}}$ : the soil mass $(\mathrm{kg})$

The calculated $K_{\mathrm{d}} \mathrm{s}$ are given in Table 4 .

As seen in the table, the $K_{\mathrm{d}}$ value increases as the initial concentration increases. The $K_{\mathrm{d}}$ also showed the trend of soil $3>$ soil $4>$ soil $2>$ soil 1 for the initial Cs concentration of 1 and 10 $\mathrm{mM}$, while soil 4 revealed the highest $K_{\mathrm{d}}$ at the $10^{-1} \mathrm{mM}$. The high $K_{\mathrm{d}}$ in the soil 3 can be easily explained by its highest surface area and CEC. However, the explanation of the high $K_{\mathrm{d}}$ in the soil 4 at the low Cs concentration requires the other mechanism besides the factors of surface area and CEC. This may be attributed to variation in the amount of two different sites for Cs adsorption; high affinity site and low affinity site in the mineral component. Indeed, Rajec et al. (1999) reported a positive correlation between total surface area and Cs sorption capacity, while inconsistent correlation between total surface area and distribution coefficient, $K_{\mathrm{d}}$.

\begin{tabular}{r|cccc}
\multicolumn{1}{l|}{$0.1 \mathrm{mM}$ Initial $\mathrm{pH}=5.8$} \\
\hline Sample mass (g) & 49.9968 & 49.9816 & 50.0403 & 49.9698 \\
\hline 0 h & 0.106 & 0.105 & 0.108 & 0.107 \\
1 h & 0.0805 & 0.0654 & 0.0679 & 0.0422 \\
2 h & 0.0777 & 0.0645 & 0.0668 & 0.0414 \\
4 h & 0.0667 & 0.0594 & 0.0708 & 0.0404 \\
8 h & 0.0683 & 0.0608 & 0.0699 & 0.0407
\end{tabular}




\begin{tabular}{|c|c|c|c|c|}
\hline $0.1 \mathrm{mM}$ & \multicolumn{4}{|c|}{ Initial $\mathrm{pH}=5.8$} \\
\hline & Soil 1 & Soil 2 & Soil 3 & Soil 4 \\
\hline Sample mass (g) & 49.9968 & 49.9816 & 50.0403 & 49.9698 \\
\hline $24 \mathrm{~h}$ & 0.0618 & 0.0457 & 0.0491 & 0.0280 \\
\hline $48 \mathrm{~h}$ & 0.0505 & 0.0363 & 0.0338 & 0.0277 \\
\hline $96 \mathrm{~h}$ & 0.0418 & 0.0282 & 0.0213 & 0.0174 \\
\hline $168 \mathrm{~h}$ & 0.0340 & 0.0236 & 0.0174 & 0.0126 \\
\hline $336 \mathrm{~h}$ & 0.0292 & 0.0213 & 0.0135 & 0.00839 \\
\hline $504 \mathrm{~h}$ & 0.0281 & 0.0208 & 0.0128 & 0.00871 \\
\hline $672 \mathrm{~h}$ & 0.0243 & 0.0220 & 0.0104 & 0.00705 \\
\hline$K_{\mathrm{d}, \text { adsorption }}(\mathrm{l} / \mathrm{kg})$ & 66.9 & 75.3 & 188 & 285 \\
\hline $1.0 \mathrm{mM}$ & \multicolumn{4}{|c|}{ Initial $\mathrm{pH}=5.6$} \\
\hline Sample mass (g) & 49.9897 & 50.0305 & 50.0279 & 50.0083 \\
\hline $0 \mathrm{~h}$ & 1.17 & 1.13 & 1.16 & 1.13 \\
\hline $1 \mathrm{~h}$ & 0.961 & 0.873 & 0.819 & 0.765 \\
\hline $2 \mathrm{~h}$ & 0.944 & 0.859 & 0.800 & 0.752 \\
\hline $4 \mathrm{~h}$ & 0.981 & 0.861 & 0.711 & 0.725 \\
\hline $8 \mathrm{~h}$ & 0.878 & 0.843 & 0.709 & 0.723 \\
\hline $24 \mathrm{~h}$ & 0.835 & 0.745 & 0.648 & 0.715 \\
\hline $48 \mathrm{~h}$ & 0.788 & 0.665 & 0.509 & 0.650 \\
\hline $96 \mathrm{~h}$ & 0.726 & 0.690 & 0.407 & 0.557 \\
\hline $168 \mathrm{~h}$ & 0.710 & 0.612 & 0.350 & 0.470 \\
\hline $336 \mathrm{~h}$ & 0.711 & 0.536 & 0.286 & 0.382 \\
\hline $504 \mathrm{~h}$ & 0.671 & 0.452 & 0.276 & 0.370 \\
\hline $672 \mathrm{~h}$ & 0.683 & 0.442 & 0.262 & 0.316 \\
\hline$K_{\mathrm{d}, \text { adsorption }}(1 / \mathrm{kg})$ & 14.4 & 31.1 & 68.0 & 51.7 \\
\hline $10 \mathrm{mM}$ & \multicolumn{4}{|c|}{ Initial $\mathrm{pH}=5.5$} \\
\hline Sample mass (g) & 50.0059 & 49.9770 & 50.0090 & 50.0043 \\
\hline $0 \mathrm{~h}$ & 11.7 & 11.5 & 11.6 & 11.6 \\
\hline $1 \mathrm{~h}$ & 11.3 & 10.9 & 10.2 & 10.3 \\
\hline $2 \mathrm{~h}$ & 11.2 & 10.7 & 10.0 & 10.5 \\
\hline $4 \mathrm{~h}$ & 11.3 & 10.6 & 9.90 & 10.5 \\
\hline $8 \mathrm{~h}$ & 11.2 & 10.7 & 9.68 & 10.3 \\
\hline $24 \mathrm{~h}$ & 10.9 & 10.5 & 9.11 & 10.0 \\
\hline $48 \mathrm{~h}$ & 10.9 & 10.3 & 8.79 & 9.73 \\
\hline $96 \mathrm{~h}$ & 10.9 & 10.0 & 8.19 & 9.50 \\
\hline $168 \mathrm{~h}$ & 10.8 & 10.0 & 8.10 & 8.32 \\
\hline $336 \mathrm{~h}$ & 10.2 & 9.83 & 8.18 & 7.89 \\
\hline $504 \mathrm{~h}$ & 9.92 & 9.06 & 8.15 & 8.33 \\
\hline $672 \mathrm{~h}$ & 9.88 & 8.96 & 8.13 & 8.18 \\
\hline$K_{\mathrm{d}, \text { adsorption }}(1 / \mathrm{kg})$ & 3.61 & 5.69 & 8.63 & 8.35 \\
\hline
\end{tabular}

Table 4. Summary of the time-dependent Cs concentrations in solutions during the adsorption experiments. The initial concentrations were determined to be $\sim 0.11, \sim 1.13$, and $\sim 11.6 \mathrm{mM}$, although they were prepared aiming $10^{-1}, 10^{0}$, and $10^{1} \mathrm{mM}$. 

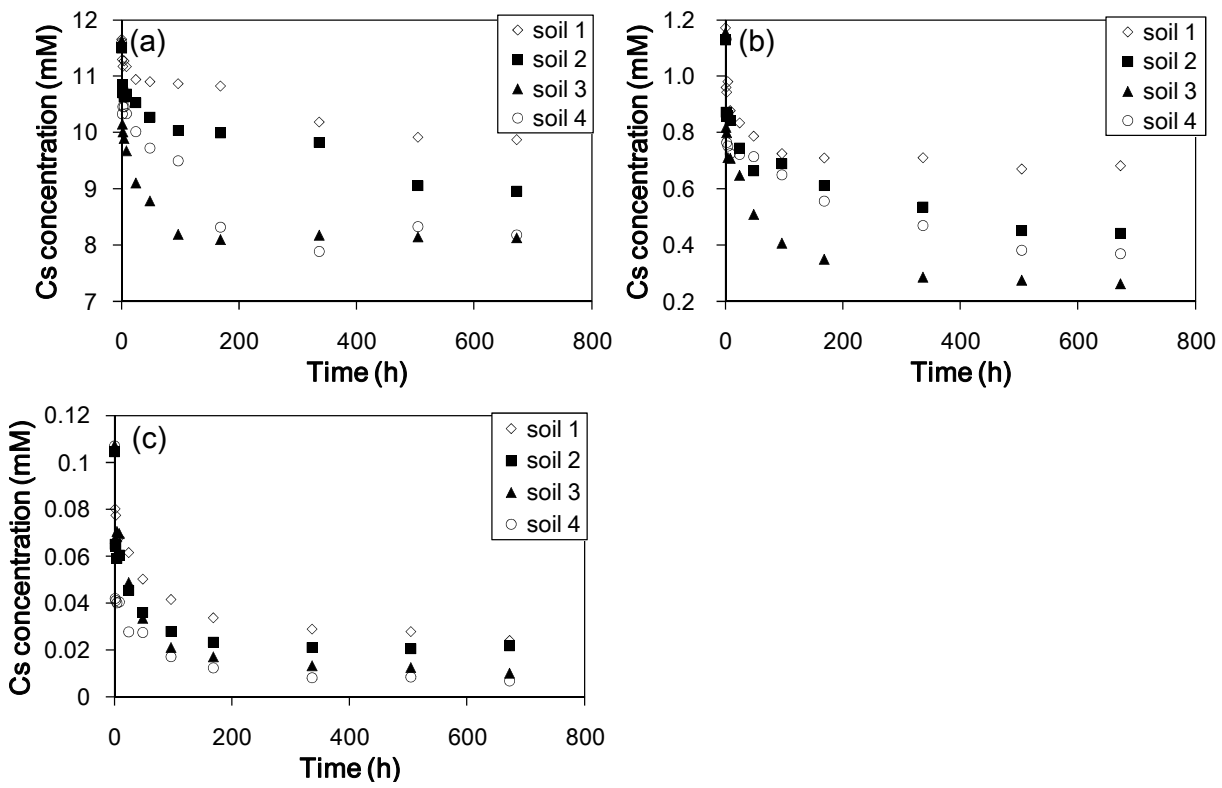

Fig. 5. Time-dependence of the Cs concentrations during the absorption experiments.

\subsubsection{Characterization of Cs-adsorbed soils by electron microscopy}

A rigorous characterization of the individual soil minerals was completed on soils 1, 3 and 4 interacted with the high Cs solution $(\sim 10 \mathrm{mM})$ using SEM. A SEM-EDX elemental map of the soil 1 sample revealed quartz, feldspar, and sheet-like aluminosilicate, which are consistent with the XRD results (Fig. 3). Cesium appears to localize only on the sheetstructured aluminosilicate. Figure 7 is the magnified image of the area indicated by the white squre in Fig. 6. The EDX point analysis indicated by the white circle revealed that the association of apatite and chloritized-biotite that contains a small amount of Cs.
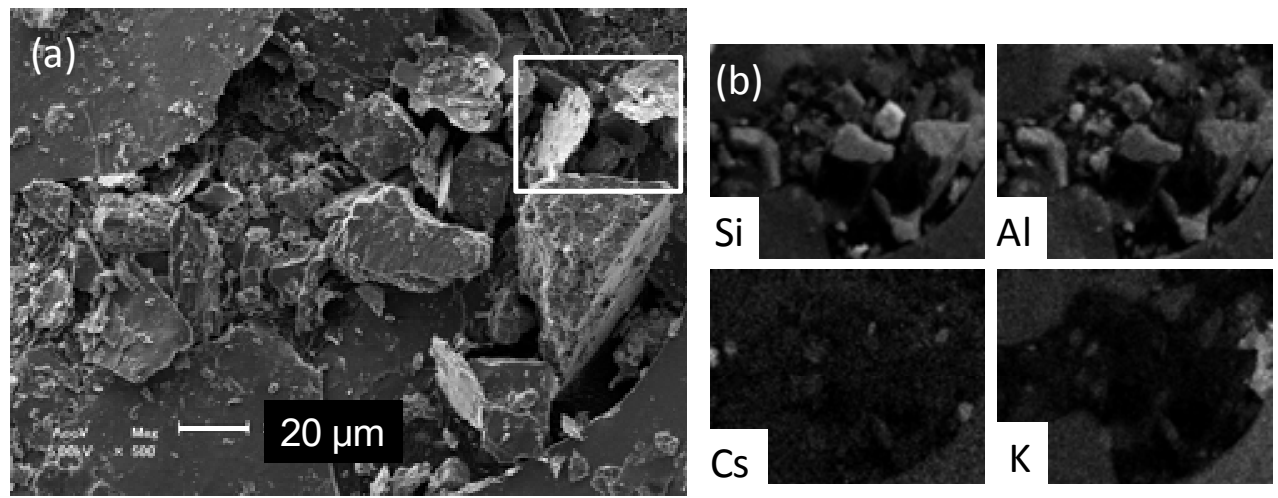

Fig. 6. Soil 1 sample. (a) Secondary electron image in SEM. (b) EDX elemental maps of the whole view in (a). 

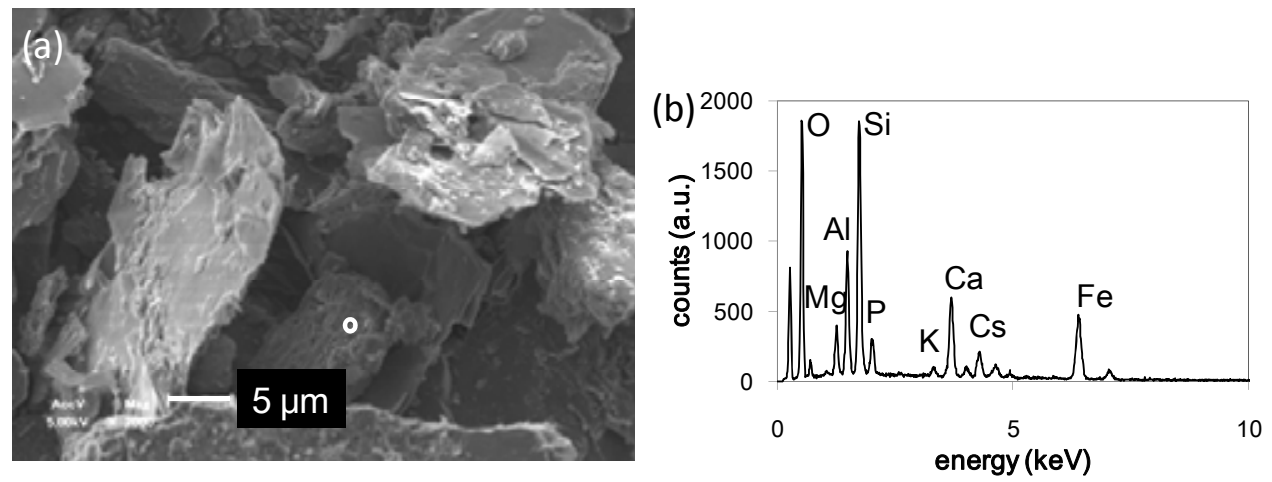

Fig. 7. The magnified image of the area indicated by the white square in Fig. 6. (a) SEM image. (b) The EDX spectrum obtained from the position indicated by the white circle.

On the other hand, the SEM-EDX elemental map and the EDX analysis of soil 3 showed the association of $\mathrm{Cs}$ with aggregates of sheet-structured aluminosilicate with illite composition (Fig. 8). Most of these illite particles were in the size $<\sim 20 \mu \mathrm{m}$, which are smaller than the chloritized biotite particles associated with Cs found in soil 1.
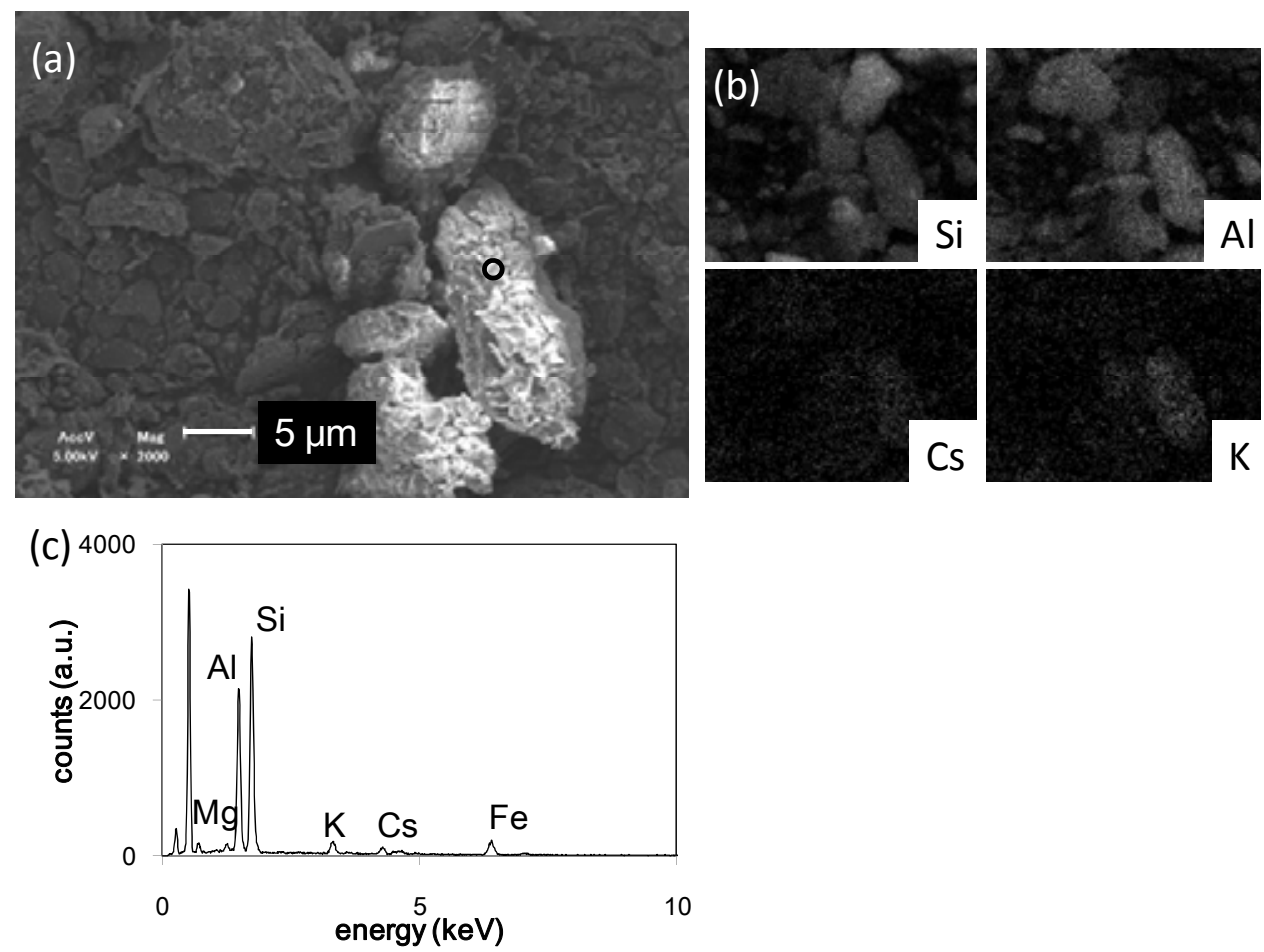

Fig. 8. SEM analysis of soil 3. (a) A secondary electron image. (b) EDX elemental maps of the view in (a). (c) The EDX spectrum of the point analysis indicated by the black open circle in (a). 
In soil 4, sheet-structured aluminosilicate at the size about several hundred micron was abundant (Fig. 9). The composition of the sheet-silicates was mostly chlorite or chloritized biotite similar to the one observed in soil 1. Figure 10 is the close-up image of a biotite particle associated with the elemental maps and the EDX point analyses. The elemental map clearly shows Cs concentration at the edge of the biotite paritcles, which is the evidence of favourable Cs adsorption at the frayed-edge site in addition to the homogeneous distribution in/on the particle. The EDX line analyses conducted on a particle clearly indicate that Cs incorporation is associated with $\mathrm{K}$ depletion at the frayed-edge (Fig. 11). The direct evidence of Cs concentraion at the frayed-edge was also reported for biotite (McKinley et al., 2004; Wang et al., 2010) and micas (Liu et al., 2003). It is also worth noting the presence of cleavage plane and the distribution of numerous smaller particles attaching on the surface of the platy particle (Fig. 11). These small particles are associated with moderately high concentration of Cs as shown in STEM-EDX maps (Fig. 12), which account for the Cs concentration in the SEM point analyses or the SEM-EDX maps.
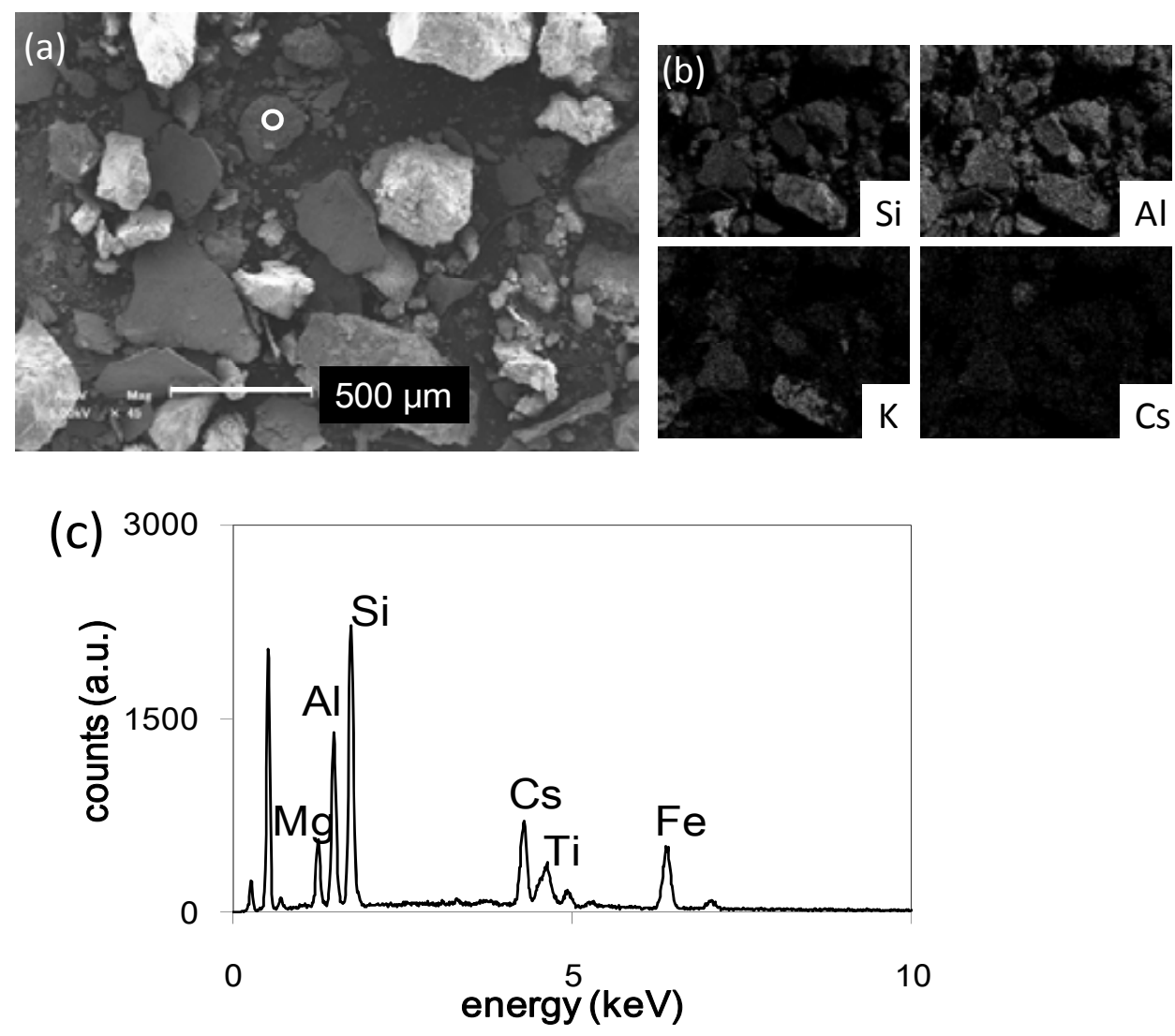

Fig. 9. Soil 4 sample. (a) A secondary electron image. (b) SEM-EDX elemental maps of the view of (a). (c) The EDX spectrum obtained from the position indicated by the white open circle in (a). 
Nuclear Accidents in Fukushima, Japan,
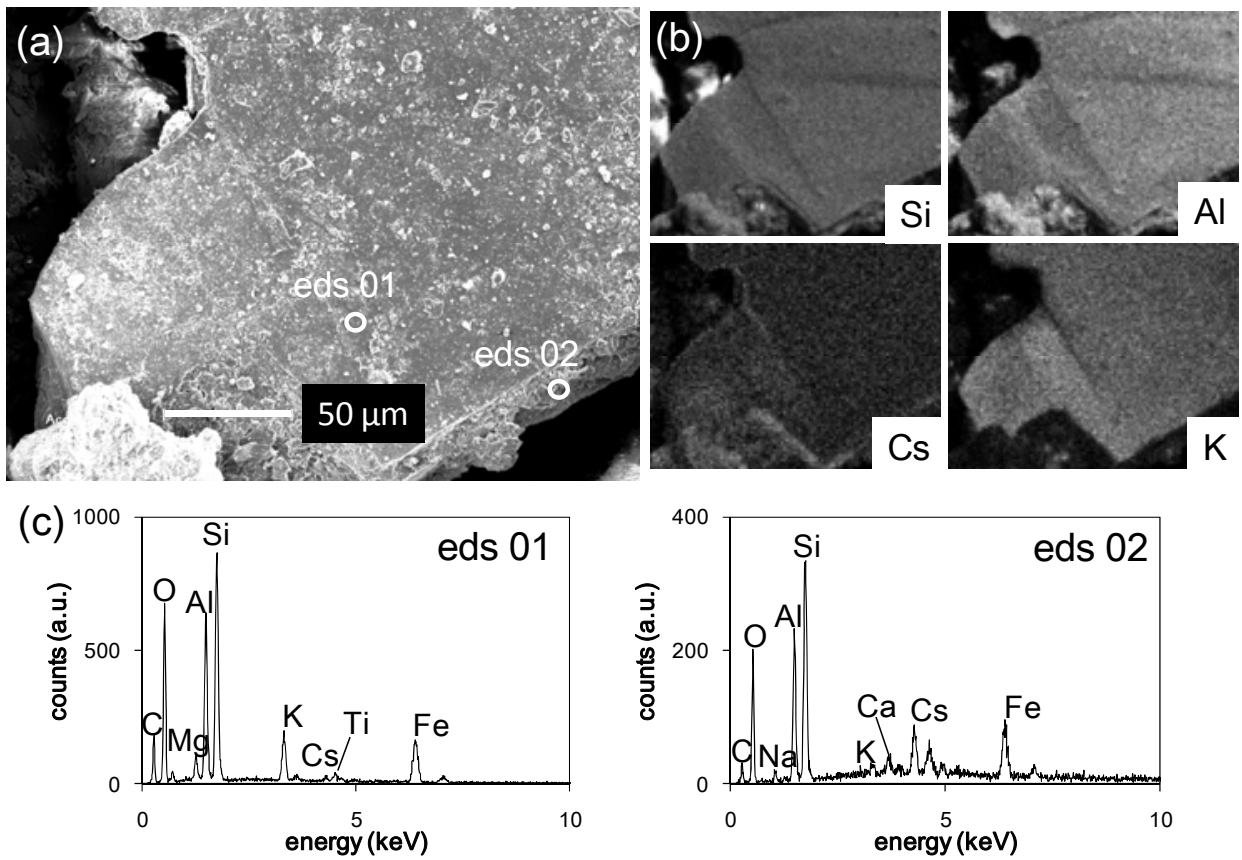

Fig. 10. Soil 4 sample. (a) Secondary electron image of a biotite particle. (b) SEM-EDX elemental maps maps. (c) The EDX spectrums at the points eds 01 and eds 02 indicated in (a).

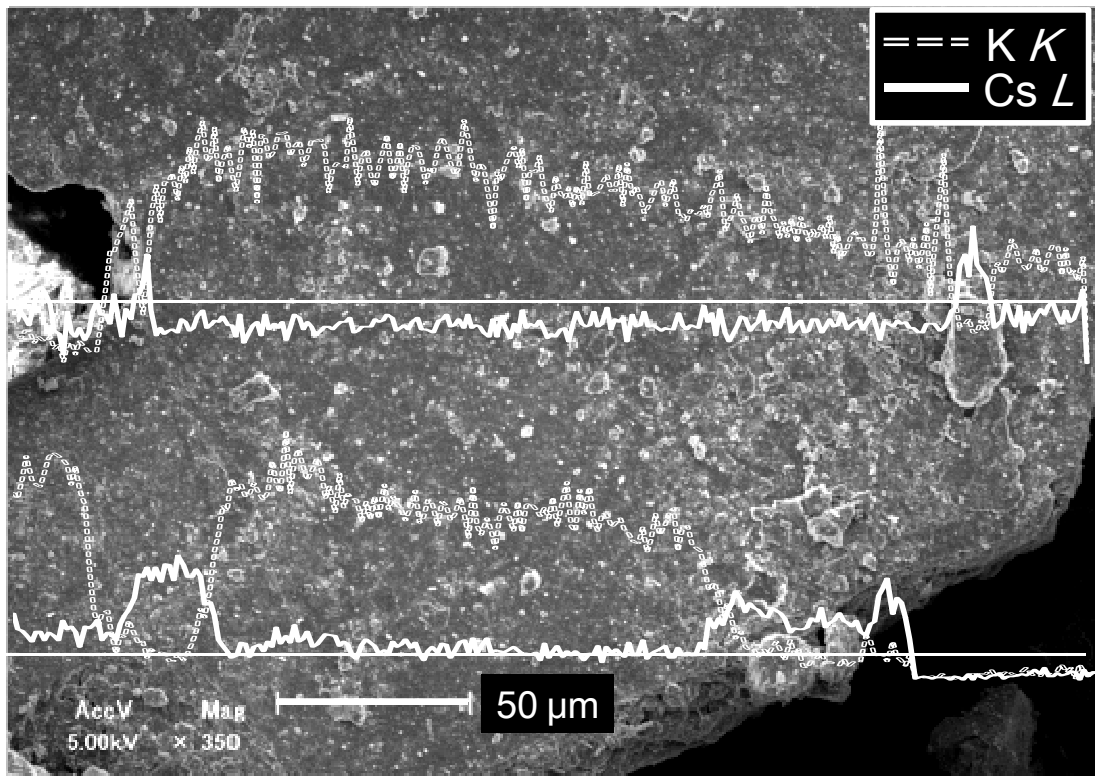

Fig. 11. EDX line scan ananlyses of the two traverses across a chloritized biotite particle. 

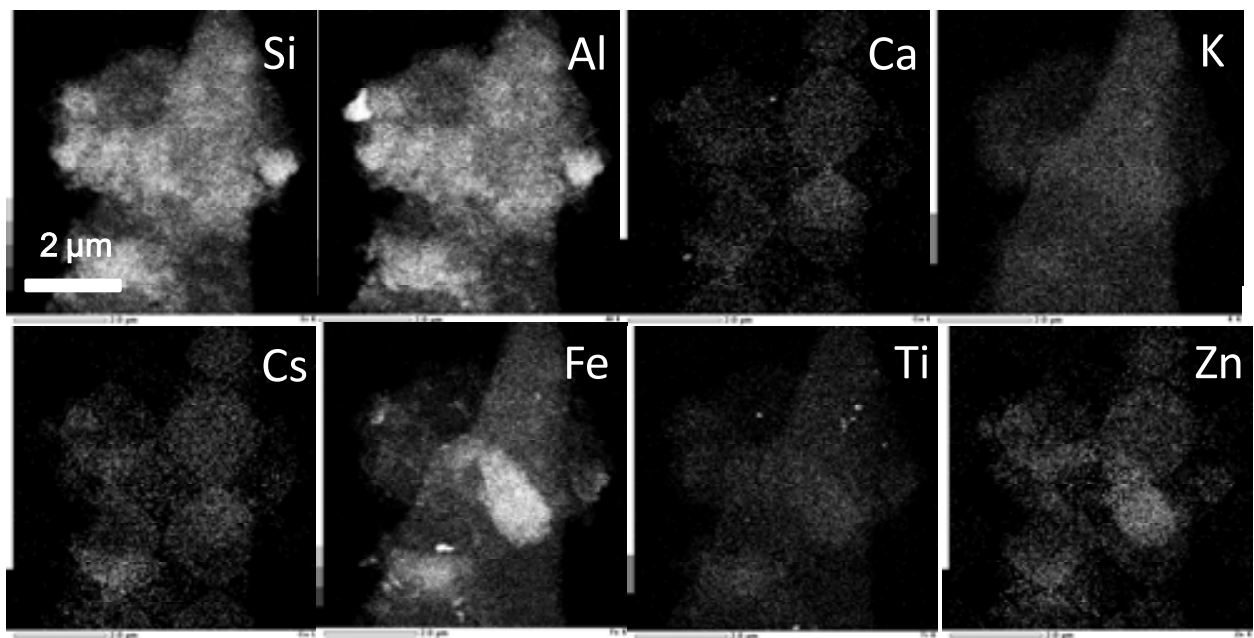

Fig. 12. STEM-EDX elemental maps of a chloritized biotite particle.

Overall, chlorite and chloritized biotite were major Cs adsorptive phase in a soils 1 and 4 . Semiquantification of these minerals indicated a wide range of $K$ concentration in chloritized biotite; however, there is a trend that Cs concentration increases as the $\mathrm{K}$ concentration decreases (Fig. 13). That is, chlorite is capable of adsorbing greater amount of Cs than biotite. (Fig. 13).

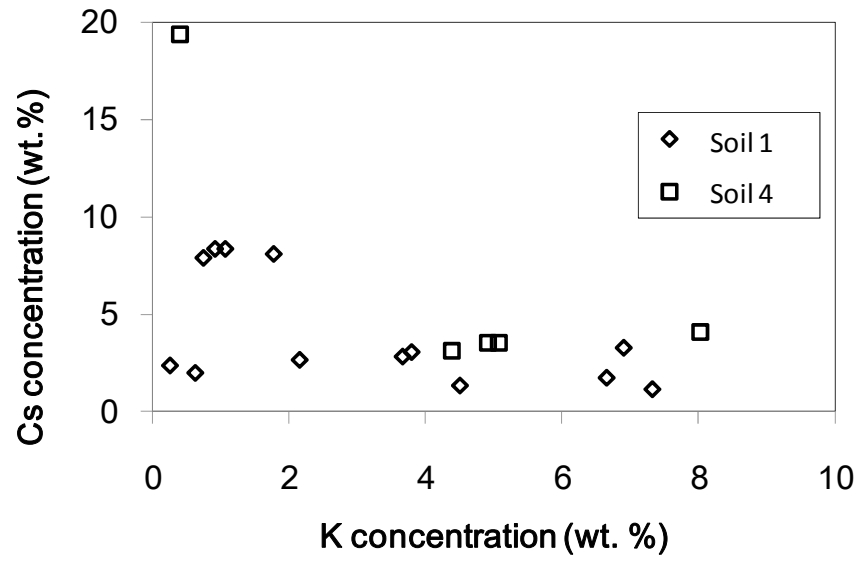

Fig. 13. The Cs concentration in biotite/chloritized biotite/chlorite particles plotted as a function of $\mathrm{K}$ concentration based on the semi-quantitative SEM-EDX point analysis.

\subsubsection{Cesium desorption in extractants}

After the adsorption experiments, the selected Cs-sorbed samples (soils 1 and 3 preliminarily contacted with $10 \mathrm{mM} \mathrm{CsCl}$ solution) were subsequently used for the desorption experiments. The time-dependent $\mathrm{Cs}$ concentrations in solutions were 


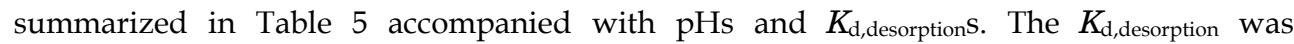
calculated by the following equation:

$$
K_{\mathrm{d}, \text { desorption }}=\frac{\left(C_{i}-C_{f}\right)-C_{f}^{\prime}}{C_{f}^{\prime}} \times \frac{W_{l}^{\prime}}{W_{s}^{\prime}}
$$

$C_{\mathrm{f}}{ }^{\prime}$ : the final Cs concentration ( $\left.\mathrm{mol} / \mathrm{l}\right)$

$W_{l}^{\prime}$ : the liquid solution volume (l)

$W_{\mathrm{s}}{ }^{\prime}$ : the soil mass $(\mathrm{kg})$

Soil 1

\begin{tabular}{|c|c|c|c|c|c|c|}
\hline Extractant & $\begin{array}{c}0.1 \mathrm{M} \\
\mathrm{MgCl}_{2}\end{array}$ & $\begin{array}{c}0.1 \mathrm{M} \\
\text { citric acid }\end{array}$ & $\begin{array}{c}0.1 \mathrm{M} \text { acetic } \\
\text { acid }\end{array}$ & $\begin{array}{c}0.1 \mathrm{M} \\
\mathrm{KCl}\end{array}$ & $\begin{array}{c}0.1 \mathrm{M} \\
\mathrm{NH}_{4} \mathrm{Cl}\end{array}$ & MilliQ \\
\hline Initial $\mathrm{pH}$ & 9.1 & 2.0 & 2.8 & 5.4 & 5.1 & 6.3 \\
\hline Sample mass (g) & 5.0032 & 5.0204 & 5.0182 & 5.0085 & 5.0024 & 5.0067 \\
\hline $0 \mathrm{~h}$ & $<0.0001$ & $<0.0001$ & $<0.0001$ & $<0.0001$ & $<0.0001$ & $<0.0001$ \\
\hline $1 \mathrm{~h}$ & 0.190 & 0.209 & 0.186 & 0.276 & 0.248 & 0.025 \\
\hline $2 \mathrm{~h}$ & 0.206 & 0.231 & 0.210 & 0.298 & 0.262 & 0.028 \\
\hline $4 \mathrm{~h}$ & 0.225 & 0.250 & 0.222 & 0.326 & 0.279 & 0.031 \\
\hline $8 \mathrm{~h}$ & 0.223 & 0.270 & 0.237 & 0.330 & 0.282 & 0.043 \\
\hline $24 \mathrm{~h}$ & 0.239 & 0.275 & 0.256 & 0.370 & 0.291 & 0.045 \\
\hline $48 \mathrm{~h}$ & 0.250 & 0.296 & 0.253 & 0.360 & 0.279 & 0.046 \\
\hline $96 \mathrm{~h}$ & 0.250 & 0.282 & 0.254 & 0.354 & 0.287 & 0.047 \\
\hline $168 \mathrm{~h}$ & 0.253 & 0.304 & 0.262 & 0.339 & 0.281 & 0.049 \\
\hline Final $\mathrm{pH}$ & 6.6 & 2.1 & 3.0 & 4.9 & 4.9 & 5.7 \\
\hline $\begin{array}{c}K_{\mathrm{d}, \text { desorption }} \\
(\mathrm{l} / \mathrm{kg})\end{array}$ & 242.5 & 194.4 & 231.7 & 170.6 & 213.8 & 1410 \\
\hline
\end{tabular}

Soil 3

\begin{tabular}{c|cccccc}
\hline Initial $\mathrm{pH}$ & 9.1 & 2.0 & 2.8 & 5.4 & 5.1 & 6.3 \\
Sample mass $(\mathrm{g})$ & 5.0011 & 5.0087 & 5.0176 & 5.0107 & 5.0065 & 5.0056 \\
\hline $0 \mathrm{~h}$ & $<0.0001$ & $<0.0001$ & $<0.0001$ & $<0.0001$ & $<0.0001$ & $<0.0001$ \\
$1 \mathrm{~h}$ & 0.994 & 0.691 & 0.635 & 1.339 & 1.233 & 0.210 \\
$2 \mathrm{~h}$ & 1.020 & 0.805 & 0.687 & 1.476 & 1.300 & 0.212 \\
$4 \mathrm{~h}$ & 1.198 & 0.872 & 0.751 & 1.593 & 1.381 & 0.235 \\
$8 \mathrm{~h}$ & 1.249 & 0.968 & 0.870 & 1.683 & 1.428 & 0.251 \\
$24 \mathrm{~h}$ & 1.317 & 1.101 & 0.855 & 1.744 & 1.499 & 0.283 \\
$48 \mathrm{~h}$ & 1.339 & 1.100 & 1.012 & 1.729 & 1.499 & 0.289 \\
$96 \mathrm{~h}$ & 1.340 & 1.088 & 1.058 & 1.730 & 1.487 & 0.300 \\
$168 \mathrm{~h}$ & 1.319 & 1.177 & 1.132 & 1.756 & 1.498 & 0.313 \\
\hline Final pH & 5.0 & 2.1 & 3.1 & 4.2 & 4.2 & 4.8 \\
\hline$K_{\mathrm{d}, \text { desorption }}$ & 66.39 & 79.11 & 83.66 & 39.81 & 53.59 & 407.3 \\
\hline$(\mathrm{l} / \mathrm{kg})$ & & & & & & \\
\hline
\end{tabular}

Table 5. Summary of the time-dependent Cs concentration during the desorption experiments on $10 \mathrm{mM}$ Cs-sorbed soil 1 and soil 3, accompanied by the solution $\mathrm{pHs}$ and $K_{\mathrm{d} \text {,desorption. }}$. 


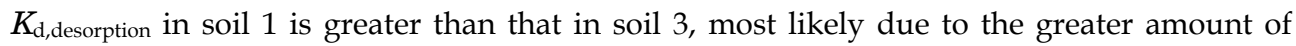
loaded Cs on the soils 3 in the adsorption experiment, which is consistent with a previous work (Wang et al., 2010). The Cs desorption efficiency of extractants is in the order of $\mathrm{KCl}>$ citric acid $>\mathrm{NH}_{4} \mathrm{Cl}>$ acetic acid $>\mathrm{MgCl}_{2}>>\mathrm{DW}$ in soil 1, whereas $\mathrm{KCl}>\mathrm{NH}_{4} \mathrm{Cl}>\mathrm{MgCl}_{2}>$ citric acid $>$ acetic acid $>>$ DW in the highly loaded soil 3 . This difference may indicate the change in efficiency depending on the amount of loaded Cs. The order found in the less Csloaded soil 1 is similar to the one previously reported; sea water $>$ groundwater $>$ sodium acetate $\sim \mathrm{MgCl}_{2}>\mathrm{DW}$ (Wang et al. 2010). Another previous study has reported that citric acid is the most effective extractant among low molecular weight organic acids owing to its three carboxyl ligands (Chiang et al., 2011). The authors suggested that protonation first occurred and the organic ligands subsequently attack $\mathrm{OH}$ and $\mathrm{H}_{2} \mathrm{O}$ group. On the other hand, our results clearly showed the highest efficiency in the use of $\mathrm{KCl}$ solution, implying the importance of cation-exchange and diffusion mechanism through the interlayer of clay minerals. Figures $14 \mathrm{a}$ and $\mathrm{b}$ are the plotted data of the Cs concentrations as a function of time, indicating that apparent equilibrium was achieved only after $24 \mathrm{~h}$, which is much faster than the case in the adsorption experiment. Chiang et al. (2011) proposed that interand intra-layer diffusion may be dominant during the first 24 hours.
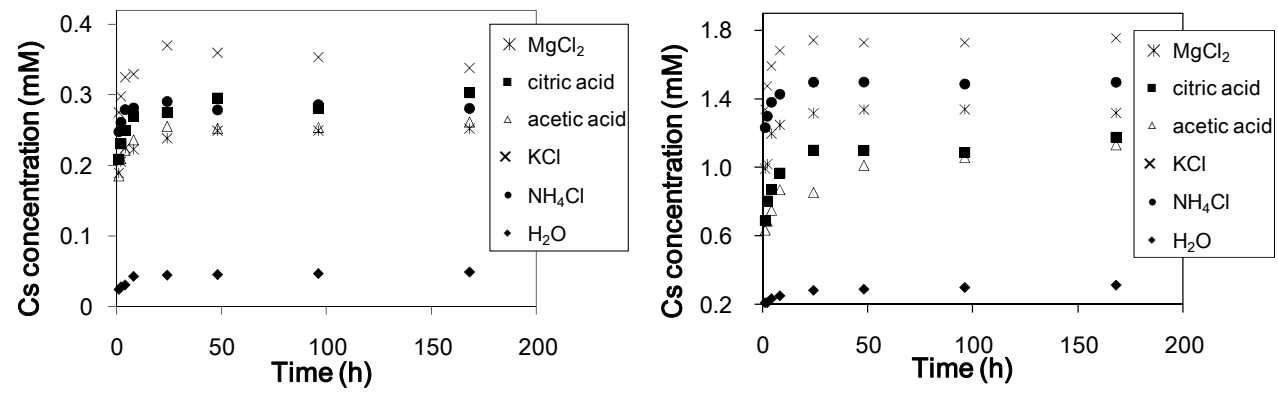

Fig. 14. Time-dependent Cs concentration during the desorption experiments.

\begin{tabular}{lcc}
\hline & Soil 1 & Soil 3 \\
\hline $\mathrm{MgCl}_{2}$ & 0.0093 & 0.0157 \\
citric acid & 0.0105 & 0.0125 \\
acetic acid & 0.0091 & 0.0083 \\
$\mathrm{KCl}$ & 0.0131 & 0.0178 \\
$\mathrm{NH}_{4} \mathrm{Cl}$ & 0.0082 & 0.0106 \\
$\mathrm{H}_{2} \mathrm{O}$ & 0.0016 & 0.0019 \\
\hline
\end{tabular}

Table 6. The apparent rate constant of Cs desorption calculated based on the data from soil 1 and soil 3. $\left(\% \sec ^{-1}\right)$.

For the quantitative comparision of efficiency of the extractants, the apparent desorption rate was calculated by drawing a regression line on the data at 1, 2, and $4 \mathrm{~h}$, of which the unit is written as $\mathrm{mM} \mathrm{h}^{-1}$. This apparent desorption rate was further converted to the dimension of second and then calibrated by the total amount of Cs on the soil in order to obtain the proportion of the amount of desorbed Cs to that of adsorbed Cs in \%, which has a unit of $\%$ sec$^{-1}$. The results obtained by the conversion clearly revealed that the apparent Cs 
desorption rate is the fastest in the case of the use of $\mathrm{KCl}$. Thus, it is concluded that $\mathrm{KCl}$ is the most effective extractant for the Cs decontamination of the Fukushima soils. However, the counter anion $\mathrm{Cl}^{-}$may cause a chloride damage. Hence, the $\mathrm{K}$-bearing chemical compounds with minimum toxicity should be explored in the future research.

\section{Conclusions}

In this chapter, we have reviewed major events related to the accident occurred at the FDNPP. A variety of fissiogenic radionuclides were released to the environment, among which ${ }^{137} \mathrm{Cs}$ is the most critical contaminant in the surface soils in the vicinity of the FDNPP. Thus, it is highly demanded to establish the efficient protocol of Cs decontamination. The present study demonstrated Cs adsorption experiments using four different types of soils collected from Fukushima. The rigorous characterization of the Cs-adsorbed soils showed that Cs is associated with both high- and low-affinity sites of illite, muscovite, biotite, chloritized biotite, and chlorite. Cesium desorption experiments were also conducted using six extractants: DW, $0.1 \mathrm{~mol} / 1 \mathrm{KCl}, \mathrm{NH}_{4} \mathrm{Cl}, \mathrm{MgCl}_{2}$, acetic acid, and citric acid. The results clearly revealed the highest efficiency of $\mathrm{Cs}$ removal when using $\mathrm{KCl}$ solution, suggesting that the K-based chemical compound is a key extractant for site remediation in Fukushima.

\section{Acknowledgments}

We are grateful to the staff of the Center of Advanced Instrumental Analysis and HVEM of Kyushu University for the technical support in TEM, SEM and ICP-MS analyses. This work was financially supported by the ESPEC Foundation for Global Environment Research and Technology (Charitable Trust) (ESPEC Prize for the Encouragement of Environmental Studies) and partly supported by Basic Research Funds from the Radioactive Waste Management Funding and Research Center.

\section{References}

Bellenger, J. P. \& Staunton, S. (2008) Adsorption and desorption of ${ }^{85} \mathrm{Sr}$ and ${ }^{137} \mathrm{Cs}$ on reference minerals, with and without inorganic and organic surface coatings. Journal of Environmental Radioactivity, 99, 831-840.

Bouzidi, A.; Souahi, F.; Hanini, S. (2010) Sorption behavior of cesium on Ain Oussera soil under different physicochemical conditions. Journal of Hazardous Materials, 184, 640-646.

Chiang, P. N.; Wang, M. K.; Huang, P. M. \& Wang, J. J. (2011) Effects of low molecular weight organic acids on ${ }^{137} \mathrm{Cs}$ release from contaminated soils. Applied Radiation and Isotopes, 69, 844-851.

Chino, M.; Ishikawa, H. \& Yamazawa et al. (1986) Application of the SPEEDI system to the Chernobyl reactor accident. JAERI-M 86-142.

Chino, M.; Nakayama, H.; Nagai, H.; Terada, H.; Karata, G. \& Yamazawa, H. (2011) Preliminary estimation of release amount of ${ }^{131} \mathrm{I}$ and ${ }^{137} \mathrm{Cs}$ accidentally discharged from the Fukushima Daiichi Nuclear Power Plant into the atmosphere. Journal of Nuclear Science Technology, 48, 1129-1134.

Comans, R. N. J. \& Hockley, D. E. (1992) Kinetics of cesium sorption on illite. Geochimica et Cosmochimica Acta, 56, 1157-1164.

Hassan, N. M. (2005) Adsorption of cesium from spent nuclear fuel basin water. Journal of Radioanalytical and Nuclear Chemistry, 266, 57-59. 
Hsu, C. N. \& Chang, K. P. (1994) Sorption and desorption behavior of cesium on soil components. Applied Radiation and Isotopes, 45, 433-437.

Khan, S. A.; Rehman, R. U. \& Kahn, M. A. (1994) Sorption of cesium on bentonite. Waste Management, 14, 629-642.

Liu, C.; Zachara, J. M.; Smith, S. C.; McKinley, J. P. \& Ainsworth, C. C. (2003) Desorption kinetics of radiocesium from subsurface sediments at Hanford Site, USA. Geochimica et Cosmochimica Acta, 67, 2893-2912.

McKinley, J. P.; Zachara, J. M.; Heald, S. M.; Dohnalkova, A.; Newville, M. G. \& Sutton S. R. (2004) Microscale distribution of cesium sorbed to biotite and muscovite. Environmental Science \& Technology, 38, 1017-1023.

MEXT (2001) http:/www.mext.go.jp/a_menu/saigaijohou/syousai/1305747.htm. Database of Ministry of Education, Culture, Sports, Science and Technology, Japan,

Missana, T.; Garcia-Gutierrez, M. \& Alonso, U. (2004) Kinetics and irreversibility of cesium and uranium sorption onto bentonite colloids in a deep granitic environment. Applied Clay Science, 26, 137-150.

Mon, J.; Deng, Y.;l Flury, M. \& Harsh, J. B. (2005) Cesium incorporation and diffusion in cancrinite, sodalite, zeolite, and allophane. Microporous and Mesoporous Materials, $86,277-286$.

Naito, M. (2011) Damage of reactor buildings at Fukushima Daiichi Nuclear Power Plants Why hydrogen explosion occurred. Journal of Atomic Energy Society of Japan, 53, 473-478 (in Japanese).

Narabayashi, T. \& Sugiyama, K. (2011) Fukishim 1st NPPs Accidents and Disaster Caused by the Pacific Coast Tsunami of Tohoku Earthquake; Lessons from evaluation of the Fukushima 1st NPPs accidents. Journal of Atomic Energy Society of Japan, 53, 387-400 (in Japanese).

NSCJ (2011) http://www.nsc.go.jp/info/20110412. Database of Nuclear Safety Commission, Japan.

Rajec, P.; Sucha, V.; Eberl, D. D.; Srodon, J. \& Elsass, F. (1999) Effect of illite particle shape on cesium sorption, Clays and Clay Minerals, 47, 755-760.

Rajec, P. \& Domianova, K. (2008) Cesium exchange reaction on natural and modified clinoptilolite zeolites. Journal of Radioanalytical and Nuclear Chemistry, 275, 503-508.

Seaman, J. C.; Meehan, T. \& Bertsch, P. M. (2001) Immobilization of Cesium-137 and uranium in contaminated sediments using soil amendments. Journal of Environmental Quality, 30, 1206-1213.

Steefel, C. I.; Carroll, S.; Zhao, P. \& Roberts, S. (2003) Cesium migration in Hanford sediment: a multisite cation exchange model based on laboratory transport experiments. $67,219-246$.

TEPCO (2011) http://www.tepco.co.jp/nu/fukushima-np/f1/index-j.html. Database of the Tokyo Electric Power Company.

Wang, T. H.; Li, M. H.; Wei, Y. Y. \& Teng, S. P. (2010) Desorption of cesium from granite under various aqueous conditions. Applied Radiation and Isotopes, 68, 2140-2146.

Yildiz, B.; Erten, H. N. \& Kis, M. (2011) The sorption behaviour of $\mathrm{Cs}^{+}$ion on clay minerals and zeolite in radioactive waste management: sorption kinetics and thermodynamics. Journal of Radioanalytical and Nuclear Chemistry, 288, 475-483.

Zachara, J. M.; Smith, S. C.; Liu, C.; McKinley, J. P.; Serne, R. J. \& Gassman, P. L. (2002) Sorption of $\mathrm{Cs}+$ to micaceous subsurface sediments from the Hanford site, USA. Geochimica et Cosmochimica Acta, 66, 193-211. 


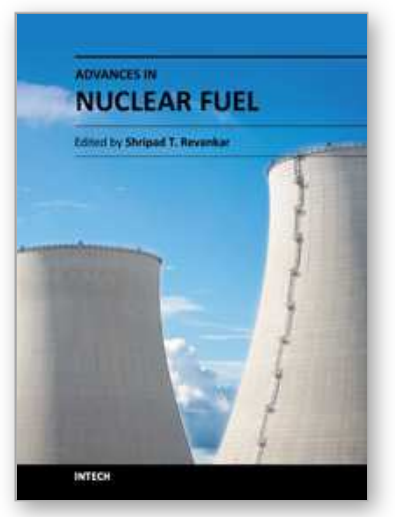

\author{
Advances in Nuclear Fuel \\ Edited by Dr. Shripad T. Revankar
}

ISBN 978-953-51-0042-3

Hard cover, 174 pages

Publisher InTech

Published online 22, February, 2012

Published in print edition February, 2012

Worldwide there are more than 430 nuclear power plants operating and more plants are being constructed or planned for construction. For nuclear power to be sustainable the nuclear fuel must be sustainable and there should be adequate nuclear fuel waste management program. Continuous technological advances will lead towards sustainable nuclear fuel through closed fuel cycles and advance fuel development. This focuses on challenges and issues that need to be addressed for better performance and safety of nuclear fuel in nuclear plants. These focused areas are on development of high conductivity new fuels, radiation induced corrosion, fuel behavior during abnormal events in reactor, and decontamination of radioactive material.

\title{
How to reference
}

In order to correctly reference this scholarly work, feel free to copy and paste the following:

Hajime Iwata, Hiroyuki Shiotsu, Makoto Kaneko and Satoshi Utsunomiya (2012). Nuclear Accidents in Fukushima, Japan, and Exploration of Effective Decontaminant for the 137Cs-Contaminated Soils, Advances in Nuclear Fuel, Dr. Shripad T. Revankar (Ed.), ISBN: 978-953-51-0042-3, InTech, Available from: http://www.intechopen.com/books/advances-in-nuclear-fuel/nuclear-accidents-in-fukushima-japan-andexploration-of-effective-decontaminant-for-the-137cs-contam

\section{INTECH}

open science | open minds

\section{InTech Europe}

University Campus STeP Ri Slavka Krautzeka 83/A 51000 Rijeka, Croatia Phone: +385 (51) 770447 Fax: +385 (51) 686166 www.intechopen.com

\section{InTech China}

Unit 405, Office Block, Hotel Equatorial Shanghai No.65, Yan An Road (West), Shanghai, 200040, China 中国上海市延安西路65号上海国际贵都大饭店办公楼405单元 Phone: +86-21-62489820

Fax: $+86-21-62489821$ 
(C) 2012 The Author(s). Licensee IntechOpen. This is an open access article distributed under the terms of the Creative Commons Attribution 3.0 License, which permits unrestricted use, distribution, and reproduction in any medium, provided the original work is properly cited. 